\title{
Research on Intercultural Communication Based on Chinese International Education in Wuhan City Circle
}

\author{
Lipei Yang \\ College of International Cultural Exchange \\ Central China Normal University \\ Wuhan, Hubei, China
}

\begin{abstract}
According to development law of Chinese international education and regional characteristics of Wuhan (city circle), the current situation of intercultural communication of international students in China and the improving paths are discussed, in order to expand horizons of teaching research and realize higher level complementation of world culture.
\end{abstract}

Keywords-Chinese international education; teaching research; Wuhan (city circle); intercultural communication; complementation of world culture

\section{INTRODUCTION}

With continuous development of "Chinese fever", Chinese international education has become an increasingly important part of Chinese higher education. International education of Chinese language is provided for foreigners who take Chinese as the second language and concerns international communication of Chinese language and culture. According to regional characteristics of Wuhan (city circle), intercultural adaptation and communication of international students in China are discussed, in order to expand horizons of teaching research and realize higher level complementation of world culture.

\section{BACKGROUND OF INTERCULTURAL COMMUNICATION} IN CHINESE INTERNATIONAL EDUCATION IN WUHAN (CITY CIRCLE)

A. In 1950, Tsinghua University Received the First Batch of Overseas Students from Eastern Europe, Symbolizing the Beginning of International Education of Chinese Language in New China

The statistics indicate by $2016,442,773$ international students from 205 countries and areas learn in 829 universities, scientific research institutions and other educational organizations in 31 provinces, autonomous regions and municipalities directly under the central government, up 45,138 people than 2015 and the growth proportion is 11.35 percent (excluding Hong Kong, Macao and Taiwan). ${ }^{[1]}$ In the past ten years, China has become the

This paper is the research result of social science fund of Hubei province (2016166), and has been presented at ICELAIC 2017 in Moscow, Russia. world's third country receiving overseas students. ${ }^{[2]}$

B. In Recent Years, Except for Beijing, Shanghai, Guangzhou and Developed Coastal Cities, Wuhan Has Become Increasingly Popular among Overseas Students In 2016, GDP gross of Hubei province ranks the 7 th. $^{[3]}$ By 2016, Hubei province ranks the top ten about the number of international students. ${ }^{[4]}$ Wuhan is the center of traffic, economy, finance, science and technology as well as politics in central China. Its urban competitiveness ranks the first in the Midwest in 2015. ${ }^{[5]}$ Comprehensive strength of Wuhan (city circle) has showed enormous regional advantage in the stiff competition, closely integrating with intercultural communication in international education of Chinese language, specifically speaking:

1) Brilliant and gorgeous Chu culture lays cultural foundation for intercultural communication

As the mainstream culture in south China, Chu culture is an important part of traditional Chinese culture. Wuhan (city circle) is the main headstream of Chu culture and promotes its development. Wuhan is a Chinese famous historic and cultural city and has inherited civilization for more than 3,500 years. Panlong city site is one of the earliest ancient cities of Shang Dynasty in Yangtze River Basin. Ezhou and Huangzhou are famous historic and cultural city at provincial level in 8 plus 1 city circle. With a history of more than 2,600 years, Jingzhou is the birthplace of Chu culture and the center of culture of three kingdoms. Yichang has had a history of more than 2,700 years. 100,000 to 200,000 years ago, "Changyang People" existed in Qingijang River Basin of Yichang. More than ten sites of the Neolithic Age are unearthed, which indicates the ancestors of Chinese nation lived long and prospered 7,000 to 8,000 years ago.

2) Colorful intangible cultural heritage bridges intercultural communication

Intangible cultural heritage of Wuhan (city circle) includes ancient language and words, oral literature, traditional folk art, traditional handicraft and skill, and folklore performances. More than 30 folk artists in Wuhan city grasp more than 20 unique skills. ${ }^{[6]}$ Traditional folk arts such as Chu opera, Chu music, Han opera, Han embroidery, clay sculpture, shadow puppet, Huangmei opera, Huangmei cross, Hongan embroidery, Hubei drum in Tuanfeng, Flower 
drum opera in Macheng, Yuejia boxing in Wuxue have been attracted attentions at home and abroad.

3) Advanced and solid scientific and educational strength provides intellectual support for intercultural communication

Wuhan (city circle) has numerous universities and scientific research institutions with intensive intelligence. According to the investigation on competitiveness of talents in 56 key cities of China in 2010, Wuhan ranks top ten in China (including Hong Kong, Macao and Taiwan) and ranks 8th in Chinese mainland. ${ }^{[7]}$ Wuhan gets into top three on ranking list of university competitiveness in Chinese cities in 2017. ${ }^{[8]}$ Good academic atmosphere, profound humanistic accumulation and close communication between universities enable international students in China to combine Chinese science and education as well as culture with the world's frontier trends.

\section{CURRENT SITUATION OF INTERCULTURAL COMMUNICATION IN CHINESE INTERNATIONAL EDUCATION IN WUHAN (CITY CIRCLE)}

\section{A. Regional Characteristics of Wuhan (City Circle) partly Restrict the Level of Intercultural Communication of International Students in China}

Overseas students just arriving Wuhan (city circle) easily have the following inadaptation in daily life: First, Wuhan (city circle) has short spring and autumn, long summer and winter and large temperature variation, letting students' physical inadaptation transform into psychological inadaptation. Second, foreign students have difficulties in accepting dietary habit in Wuhan (city circle) with heavy oil, salt and pepper within a short time. Finally, it is difficult to understand and learn dialect of Wuhan (city circle), which is greatly different from mandarin. The international students' initiative of mental adaptation weakens, and they are antagonistic to surroundings.

\section{B. The Teaching of Chinese as a Foreign Language} Focuses on Language Teaching but Neglects the Effects of Culture with Wuhan (City Circle) Characteristics

If cultural and literary educations are neglected in the teaching of Chinese as a foreign language, overseas students will fail to learn and use Chinese language, which goes against the original intention of international education of Chinese language. If cultural elements with regional characteristics of Wuhan (city circle) cannot be integrated in international education of Chinese language, it will influence the depth and width of international communication of Chinese language.

\section{Overseas Confucius Institutes (Classrooms) of Universities in Wuhan (City Circle) Face New Challenges}

After overseas Confucius Institutes (classrooms) of universities in Wuhan (city circle) enjoy "honeymoon period" locally, it incurs query. Some people involved call it "Trojan Horse" for penetration of Chinese culture. ${ }^{[9]}$

\section{Potential Joint Forces of Public Diplomacy and Radiation Influence of Wuhan (City Circle) Haven'T Been Given Full Play}

Insufficient effective promotion of regional characteristics of Wuhan (city circle), unclear short term and long term educational plan, single channel and means of absorbing international students in China, weak combination between education for international students in China and economic and social development make Wuhan (city circle) fails to form brand with regional characteristics related to education for international students in China, let alone giving play to the joint forces of public diplomacy and radiation influence.

\section{IMPROVING PATHS FOR INTERCULTURAL} COMMUNICATION IN CHINESE INTERNATIONAL EDUCATION IN WUHAN (CITY CIRCLE)

\section{A. Formulate Entrance Requirements for International Students in China, in Order to Improve Their Cultural and Intellectual Levels}

According to characteristics of Wuhan (city circle), cultivation units can begin from preparatory education, formulate entrance requirements for international students in China and expand enrollment scale. Compile and revise proper syllabus, teaching materials and educational schemes, and strengthen the construction of teaching staff and courses with regional characteristics, in order to improve overseas students' cultural and intellectual levels, and "adapt to new cultural environment through self-repair”.[10]

\section{B. Integrate Culture of Wuhan (City Circle) in the Teaching of Chinese as a Foreign Language}

In the class of ancient Chinese literature, the author leads students to learn Yellow Crane Tower, poetry of Cui Hao who is a poet in Tang Dynasty. The poetry is praised as "the first in eight-line Chinese poem with seven characters to a line of people in Tang Dynasty". Images in the poetry such as immortals, Yellow Crane Tower, sunshiny river surface, trees in Hanyang, Parrot Cay have vivid color and enhance each other's beauty, full of poetic and pictorial splendor. Wuhan even Hubei enjoys popularity at home and abroad for the prestigious cultural card. Overseas students recite poetry when visiting the Yellow Crane Tower and admire beautiful mountains and rivers and traditional culture in Wuhan (city circle). In the class of modern and contemporary Chinese literature, the author helps overseas students to know about Wuhan city through teaching the Life Show and the Troubles of Life written by $\mathrm{Chi} \mathrm{Li}$, the City of Wuchang and the Scenery written by Fang Fang.

Teachers can give full play to the guidance function of New HSK examination, integrate Chinese culture in teaching, research and examination and excavate elements of Wuhan (city circle). For example, the 70th question in New HSK-5 (H51001) relates to "the story about Hua Mulan", the listening content of the 48th to 50th questions in New HSK-6 (H61221) relates to the story of Bo Ya and Zhong Ziqi. 
C. Smoothly Realize "Soft Landing” of Public Diplomatic Function in Overseas Confucius Institutes (Classroom) in Universities of Wuhan (City Circle) to Realize "Connotative" Sustainable Development

Under the premise of maintaining language and cultural security, and respecting its language and cultural habits in local areas, understand requirements of local people for foreign culture and create communication like "friends" and "partners". Meanwhile, intensify publicity and research of Wuhan (city circle) and let overseas students feel the beautiful, prosperous and developmental Wuhan (city circle). Except for introducing scenic spots and historic sites such as Yellow Crane Tower, Hubu Lane, Ancient Qin Tai, Qingchuan Pavilion, Tanhualin, Xingyin Pavilion and East Lake to them, we can recommend well-known universities, Museum of Wuchang Uprising of 1911 Revolution, Wuhan Yangtze River Bridge, Baishazhou Bridge, Yingwuzhou Bridge, Wuhan Automobile Industrial Base, Wuhan Donghu New Technology Development Zone, Wuhan Iron and Steel Group, Wuhan Metro, Wuhan Museum of Science and Technology, "Wuhan Citizen's Home". Overseas students can learn Chinese language, experience the rapid development of China, draw the distance to Wuhan (city circle) close and "reach 'Target Language Compensation' at higher level", $" 11]$.

\section{Depend on External Government Sectors to Establish} Foreign-related Public Information Platforms, in Order to Deliver "Wuhan Voice" and Narrate "Good Stories in Wuhan",

Wuhan is the strategy support of "rise of central China" and the important keeper of "the Belt and Road". Achievements of its urban construction benefit local people and let international students feel the huge achievements brought by the reform and opening up. In recent years, most universities in Wuhan (city circle) organize activities such as "Jing-Chu Culture Popularization", "Tour of Seeking Roots", "Class of Teaching Chinese Culture", and "Experience Camp of Chinese Culture" held by China Scholarship Council, Office of Chinese Language Council International, and Foreign Affairs Office of governments of Hubei Province and Wuhan (city circle). Culture experience activities held by government foreign affairs office and free walking of overseas students bring out the best in each other, so that they can contact culture of Wuhan (city circle). At the meantime, competent foreign affairs department can take advantage of Internet Plus and establish foreign-related public information platforms, in order to enable overseas students to convey what they see and feel to their compatriots timely through modern media and form benign "butterfly effect".

\section{CONCLUSION}

TCSL teachers in universities of Wuhan (city circle) should pay attention to requirements of overseas students' development, accurately and effectively use regional advantage to realize intercultural adaptation and communication, in order to better promote international education for Chinese language and communication, and create new type harmonious living space for culture at home and abroad.

\section{REFERENCES}

[1] Official website of the Ministry of Education of the People's Republic of China, Statistics of International Students in China in 2016, Mar. 1, 2017

[2] Deng Hui. International Students Studying in China, Attentions Are Paid to What Kind of Signals [N], Guangming Daily, Apr.7, 2015 (the 3rd Edition)

[3] Wen Juan. Economic Aggregate Leap to the 7th, Having Created the Best Level Since the Establishment of the People's Republic of China [N], Hubei Daily, Jan.20, 2017 (the 3rd Edition)

[4] Same as [1].

[5] Zhou Shunyao. Ranking of 2015 Urban Competitiveness: Wuhan Ranks First in the Midwest [N], Changjiang Times, May 25, 2015 (the 6th Edition)

[6] Yao Weijun. Thinking on Construction of Culture Soft Power of Wuhan City Circle [J], Study and Practice, 2009 (7): 134-139

[7] Zhang Huaimin. Selection of Paths to Improve Urban Culture Soft Power: Research on Development of Culture Soft Power of Wuhan [J], Science and Technology Progress and Policy, 2013 (5): 47-51

[8] He Yingchun. Ranking List of University Competitiveness in Chinese Cities in 2017, Beijing, Shanghai and Wuhan Rank Top Three [N], People's Daily, Mar.27, 2017 (the 4th Edition)

[9] Wu Ying. Reflection on Strategy of Chinese Cultural Transmission of Confucius Institute [J], Academic Forum: 2009 (7): 141-145

[10] Li Xiaoyan. Research on Influence of Cultural Intelligence of International Students in China on Intercultural Adaptation [J], Journal of Management, 2012 (12), 1779-1785

[11] Li Yuming. Discussion on Language Education of Confucius Institute [J], Language Teaching and Linguistic Studies, 2014 (4): 1-8 